excised on August 20,1948, and a piece of London Hospital sterile amniotic membrane (Morley's process-fat-free) of the same size as the raw area, was sutured into position.

The appearance of the eye some four days after the operation is shown in Fig. 2, August 24, 1948, The appearance of the conjunctiva a month after operation is shown in Fig. 3, September 29, 1948.

It is felt that these representations of the appearance of the eye during the regeneration period of the conjunctiva are of interest. Also they indicate a possible use for amniotic membrane in the early treatment of ophthalmic wounds in war-time, particularly in the mobile ophthalmic units in forward areas.

\title{
UNUSUAL OCULAR FOREIGN BODY
}

\author{
BY \\ Nirmal Kumar Ghose \\ Calcutta
}

VARIOUS authors have reported the occurrence of different types of intra-ocular worms, but the occurrence of a snail in the eye must be of extreme rarity, if indeed it has ever been known.

\section{Case Report}

K.R.M.. a 16-year old male, came on October 1, 1948, with a history of irritability in the left eye together with deep left orbital aching of one week's duration. These symptoms began about half an-hour after washing his face in a pond.

Examination revealed superficial punctate keratitis and the inferior palpebral conjunctiva was congested. There were large follicles in rows upon the lower fornix. While the lower fornix was being examined a small snail emerged apex first from under the conjunctiva, and started moving across the palpebral conjunctiva. It was picked up by a swab-stick, and preserved in formalin.

On more detailed examination corneal sensation was found lost and the pre-auricular gland enlarged. Slit-lamp examination showed typical sub-epithelial infiltration and blebs.

The deep boring pain passed away about two minutes after tbe emergence of the snait. The keratitis cleared up completely with dark glasses, normal saline, Ung. Atropine 1 per cent., and Sterodin-2 c.c. every other day, and by October 12, 1948, he was cured.

The snail was taken to the Department of Helminthology in thc School of Tropical Medicine, and was identified as a young Vivipara Bengalensis,

The size of the snail is vertically apex to base one mm., and horizontally $2 \mathrm{~mm}$. I was told that a week earlier the size would have been no larger than a grain of sand. 


\section{Discussion}

How did such an unusual foreign body go under the conjunctiva? These organisms do not have teeth, and they do not burrow. Probably the patient, feeling the gritty sensation of a foreign body in the eye, gave a good rub, and the snail's sharp shell-apex punctured the conjunctiva and went under it.

I was also informed that it can easily survive in such sheltered conditions, but rapidly dies on exposure to air. Whether the associated corneal condition was fortuitous or a complication is uncertain, but we were seeing a few K.P.S. cases every day at that period, so it may have been a coincidence.

My thanks are due to Dr. A. K. Mukherjee and Dr. N. Bhaduri, Department of Helminthology. School of Tropical Medicine, for valuable aid and advice, and to Dr. A.C. Ukil, Superintendent, Medical College Hospitals, Calcutta, for permission to publish this case.

\section{OBITUARY \\ - PROFESSOR V. ROSSI}

VINCENZO Rossi qualified as a medical man at Naples University in 1914 , and became an assistant at the ophthalmic clinic of that university in the following year. Here he worked for a number of years under the late Professor Angelucci. In 1929 he was appointed Professor of Ophthalmology at the University of Modena, and afterwards at Pisa University. His academic output covered a wide range of subjects, including trachoma, endocrinology and glaucoma, but perhaps his chief interest lay in linking-up ophthalmic signs with general derangement of the constitution. His first and only visit to England was made in April this year, when he attended the annual Congress of the Ophthalmological Society of the United Kingdom, but long before that time his work and reputation had become familiar to readers all over the world. The news of his sudden death towards the end of June was distressing, because Professor Rossi was a courteous and accomplished gentleman, typical of Latin civilisation at its best. He will be greatly missed at the International Congress which he had looked forward to attending in 1950 . Readers will deeply sympathise with the members of his family circle in their heavy loss. 